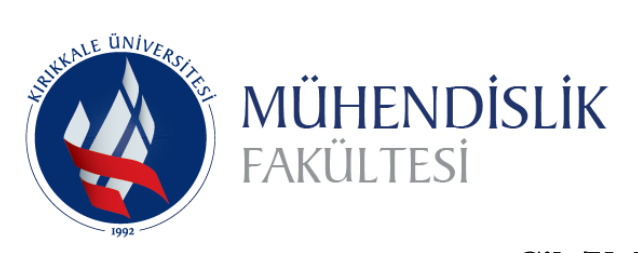
Uluslararası Mühendislik
Araştırma ve Geliştirme Dergisi
International Journal of
Engineering Research and
Development

UMAGD, (2020) 12(2), 638-647.

Cilt/Volume:12 Sayı/Issue:2 Haziran/June 2020

Araştırma Makalesi / Research Article

\title{
Polypropylene/Chemical Blowing Agent Foams: Effect of the Injection Speed and Core Back Distance on Microstructure and Mechanical Properties
}

\author{
Meral Akkoyun*1 $^{\text {iD }}$, İbrahim Badem² ${ }^{\text {iD }}$, Mert Emre Öztoksoy ${ }^{3}$ iD, Yeşim Aslan $^{4}$ iD \\ ${ }^{1}$ Bursa Technical University, Department of Polymer Materials Engineering 16310, Bursa, TURKEY \\ ${ }^{2}$ TOFAŞ Turkish Automotive Factory Corporation, 16110, Bursa, TURKEY \\ ${ }^{3}$ Farplas Otomotiv Corporation, 41420, Kocaeli, TURKEY \\ ${ }^{4}$ Karel Kalip Corporation, 34959, Istanbul, TURKEY
}

Başvuru/Received: 31/03/2020

Kabul / Accepted: 23/06/2020

Çevrimiçi Basım / Published Online: 30/06/2020

Son Versiyon/Final Version: 30/06/2020

\begin{abstract}
In recent years, many parts of the automotive industry, previously made of metal, has been passed to polymers due to their light weight, ie lower carbon emission and fuel consumption advantage. The aim of this work was to investigate the microstructure and mechanical properties of chemical foaming agent added polypropylene foam samples produced by injection molding. In particular, the effects of injection speed and core back distance on the evolution of cell diameter, compact outer layer thickness, cell density and mechanical properties were examined. In the first step the effect of various injection speeds $(110 ; 125 ; 140 \mathrm{~mm} / \mathrm{s})$ was investigated. Then, various core back positions $(0 ; 0.7$ and $1.5 \mathrm{~mm})$ were analyzed at a constant injection speed $(110 \mathrm{~mm} / \mathrm{s})$. The results showed an increase of the cell diameter, the compact outer layer thickness and the elastic modulus as the injection speed increases. In addition, an important effect of the core back distance was observed with the presence of a critical core back distance. Below this critical value, the cell diameter and the elastic modulus drop due to a notable decrease of the skin layer thickness. Above this critical value, the cells started to collapse and lose their circularity.
\end{abstract}

Key Words

"Polypropylene Foam, Chemical Blowing, Injection Molding, Core back, Microstructure, Mechanical Properties" 


\section{Introduction}

For many years standard plastic injection method has been used in industry and several academic studies take place in the literature. Lots of metal parts were replaced with plastics because of the cost advantage, weight reduction, and processability in high tolerances, surface quality and many other advantages. Polymeric foams seem to be the new trend to replace compact plastics. Polypropylene (PP), due to its excellent thermal and mechanical properties and particularly its high mechanical and heat resistance, is one of the most widely used thermoplastics. Therefore, the use of PP in automotive reached more than $47 \%$ compared to the total use of polymer materials (Lyu and Choi 2015)

Three methods of producing polymer foams take place in the literature: chemical foaming, physical foaming and glass bubble. (Ries et al. 2013) Chemical foaming has some advantages compared to other methods. Particularly, no extra equipment is necessary for chemical foaming process whereas physical foaming process needs for example metering system and gas cylinder. The raw material costs are lower compared to glass bubble. Chemical foaming process is similar with standard injection process. But the fluidity and solidification behaviors of the plastic change totally when chemical blowing agents (CBA) are added to create polymer foams. It is possible to produce several parts in different wall thicknesses, densities and mechanical properties using the same polymer/chemical blowing agent mixture only by changing the process parameters and core back set up of the mold. The core back distance and injection speed have a huge influence on microstructure and mechanical properties of PP foams and very few studies can be found in the literature (Wu et al. 2018, Reglero Ruiz et al. 2016, Reglero Ruiz et al. 2015, Wu et al. 2019)

The core-back system is actually an advanced technology allowing an increase of the weight reduction. In this technology, the core back represents an additional step during the injection molding process which provides a free volume for polymer foaming. In this way, the manufacturing of foamed plastic parts becomes more achievable with an increased weight reduction. (Wu et al. 2018, Reglero Ruiz et al. 2016, Reglero Ruiz et al. 2015, Wu et al. 2019, Jahani et al. 2014, Stumpf et al. 2011, Zhao et al. 2017, Miyamoto et al. 2014, Sporrer and Altstadt 2007, Chu et al. 2016, Wang et al. 2017, Ishikawa and Ohshima 2011, Ameli et al. 2015, Shaayegan et al. 2017, Ishikawa et al. 2012, Ameli et al. 2014) Wu et al. (2018) examined the mechanical properties of polymeric foams composed of syndiotactic PP mixed with azodicarbonamide as chemical blowing agent and produced by injection molding and core back technologies. They showed that the core back technique decreases the defects present on the surface of specimens and improved the mechanical properties even at similar weight drop conditions. More specifically, compared with conventional samples obtained using the same technology, the results point out that the mechanical properties (tensile strength, notch impact strength and elastic modulus) are improved at between $42.55 \%$ and $54.10 \%$. Another study conducted by Reglero Ruiz et al. (2016) on the fabrication of pure PP foams with citric acid based CBA by injection molding and core back system combined with gas counter pressure technique demonstrated that the type of CBA is an important parameter that affects the final microstructure of the foams. They demonstrated that the CBA containing citric acid and sodium bicarbonate leads to bubble sizes approximately twice larger compared to those obtained with the CBA containing only citric acid. In addition, other studies showed that the use of common physical blowing agents in injection molding combined with the core back technique, due to their high foaming power, involves usually good foaming effects, but in the case of CBAs, due to their low foaming power, it is more complex to produce an entire piece of parts. (Reglero Ruiz et al. 2015, Tomasko et al. 2009)

There are few experimental studies on the effect of core back distance on the final properties of CBA added PP foams obtained in core back and injection molding processes. The present work is focused on the effect of process parameters and particularly the injection speed and the core back distance on the microstructure and the mechanical properties of CBA added polypropylene foams.

\section{Materials And Methods}

\subsection{Materials}

A high flow PP in granule form (Hostacom TYC 469 F) supplied from Basell / Netherlands (Melt flow rate: $37 \mathrm{~g} / 10$ min) was used in this study and Hydrocerol ITP 825 supplied from Clariant / Switzerland was chosen as a chemical blowing and nucleating agent. PP and CBA were utilized as received. The melting temperature of PP was determined from a TA Instruments DSC25 Differential Scanning Calorimeter at a heating rate of $10^{\circ} \mathrm{C} \cdot \mathrm{min}^{-1}$ and the decomposition temperature of CBA was obtained from the thermogravimetric analysis curves obtained under nitrogen gas and at a heating rate of $20^{\circ} \mathrm{C} . \mathrm{min}^{-1}$ using a Perkin Elmer STA6000. The results were presented in Figure 1 and Figure 2.

According to Figure 1a, the melting temperature of the PP was determined as $160^{\circ} \mathrm{C}$. In the case of CBA, from Figure $1 \mathrm{~b}$, two different melting points can be observed: $100^{\circ} \mathrm{C}$ and $190-230^{\circ} \mathrm{C}$. The less important peak observed around $100^{\circ} \mathrm{C}$ represents the melting temperature of polyethylene, while the peak value situated between $190^{\circ} \mathrm{C}$ and $230^{\circ} \mathrm{C}$ results from the decomposition of the chemical blowing agent which is citric acid in our case. (Ruiz et al. 2015)

From Figure 2, it can be observed that the chemical foaming agent contains about $20 \%$ active component determined as citric acid from differential scanning calorimetry results. In addition, the decomposition temperature of $\mathrm{CBA}$ was detected as $200^{\circ} \mathrm{C}$ according to Figure 2 . The second important weight loss obtained around $420^{\circ} \mathrm{C}$ represent the decomposition of polyethylene. 

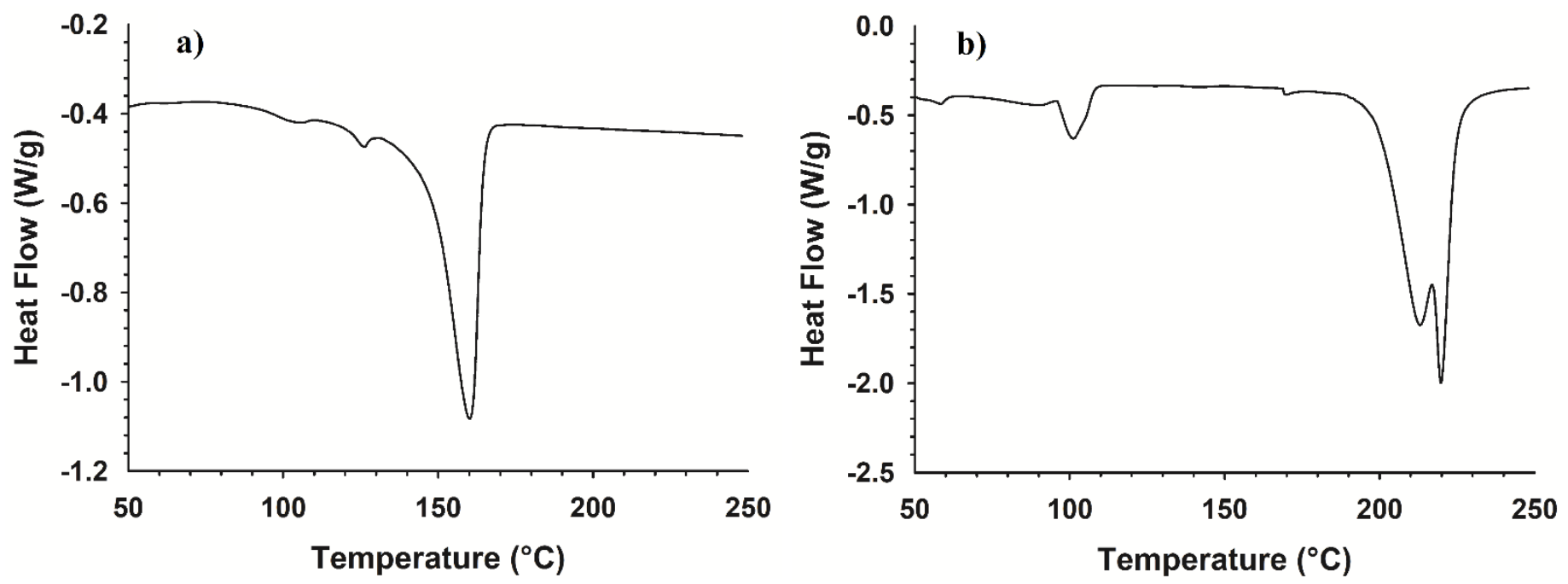

Figure 1. Differential scanning calorimetry curves: (a) PP and (b) CBA.

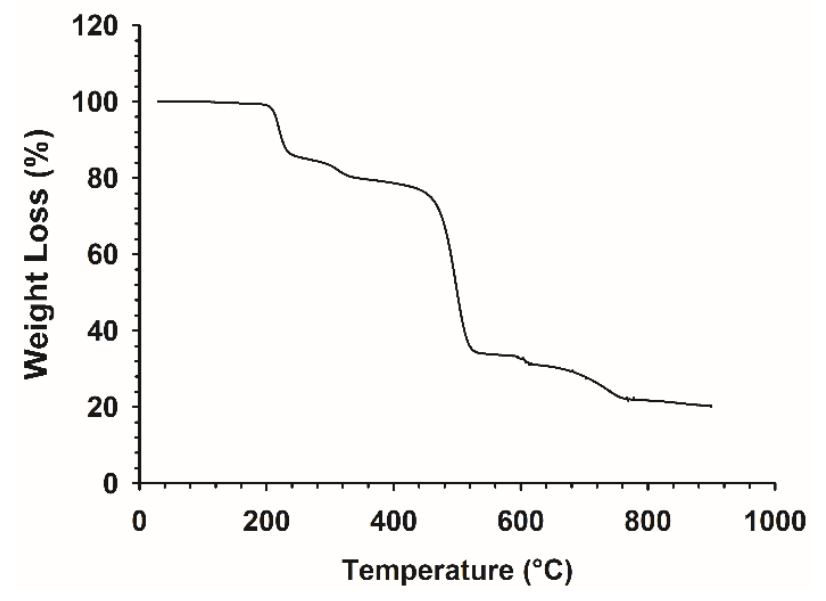

Figure 2. Thermogravimetric analysis curve of CBA.

\subsection{Preparation of PP / CBA Foams by Injection Molding Process}

PP/CBA blends were prepared using a precision dozing and a mixture unit. The content of CBA was fixed at 1.5 wt.\% for all experiments. A special injection molding machine of Krauss Maffei which was able to inject in high speeds and has a core back control feature (Figure 3) was used in this study. The amount of the material and the pressures were gradually increased and set at full fill point. During the process the mold temperature was set to $30^{\circ} \mathrm{C}$. The temperatures of the screw were fixed as 190-215-220-220-225225-220-195-195-190 ${ }^{\circ} \mathrm{C}$ in the different zones of the extruder. In this way, the decomposition of CBA and the gas outlet were started inside the mold; not in the screw of the injection machine in order to eliminate premature loss of gas. As mentioned in Figure 2 the decomposition temperature of $\mathrm{CBA}$ is about $220^{\circ} \mathrm{C}$. During the first experiments, three different injection speeds were tested $(110,125$ and $140 \mathrm{~mm} \cdot \mathrm{s}^{-1}$ ). The mold was in no-core back position. The other parameters were unchanged. In the second experiments; three different core back positions were evaluated (core back distance: $0 \mathrm{~mm} ; 0.7 \mathrm{~mm}$ and $1.5 \mathrm{~mm}$ ). In the same way, the rest of the parameters remain unchanged.

\subsection{Characterization Methods}

The microstructure of the foams was characterized using a LIC-BM2500 optical microscope at a magnification of X10 and micrographs were recorded for each samples prepared at different injection speeds and core back distances. Images were obtained for foam sections perpendicular to the surface. The compact outer layer thickness and cell size measurements were exhibited using Image $\mathbf{J}$ software and the mean compact outer layer thickness and cell diameter were calculated from at least 80 cells using optical microscopy pictures acquired for sample sections perpendicular to the surface. In the same way the cell density values or number of cells/cm 2 were obtained from optical microscopy images and were calculated from at least 80 cells using optical microscopy pictures acquired for sample sections perpendicular to the surface. Tensile tests were realized on samples prepared based on ASTM D638 (type I). A universal testing machine (SHIMADZU-AGS-X, $10 \mathrm{kN}$ ) with a cross-head speed of $15 \mathrm{~mm} / \mathrm{min}$ was used for these measurements. 


\section{Mold}

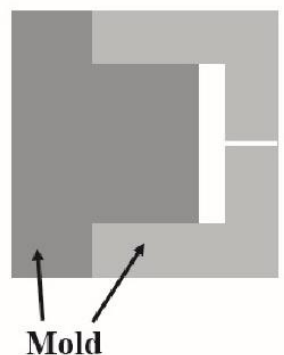

2. Filling

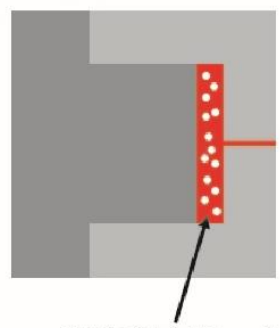

PP/CBA blend

\section{Mold-opening}

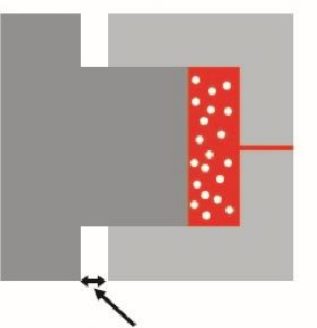

Core back distance

Figure 3. Schematic representation of the core back control feature.

\section{Results and Discussion}

\subsection{Effect of Injection Speed on the Properties of PP/CBA Foams}

\subsubsection{Optical microscopy results}

Optical microscopy images of PP/CBA foams prepared at various injection speeds $(110,125$ and $140 \mathrm{~mm} / \mathrm{s})$ were given in Figure 4. For these measurements only one parameter, the injection speed, was changed to evaluate its real impact. Furthermore, the crosssectional micrographs were analyzed in order to monitor the evolution of the microstructure and in particular, the cell size, cell density and thickness of the compact outer layer of PP/CBA foams as a function of the injection speed.
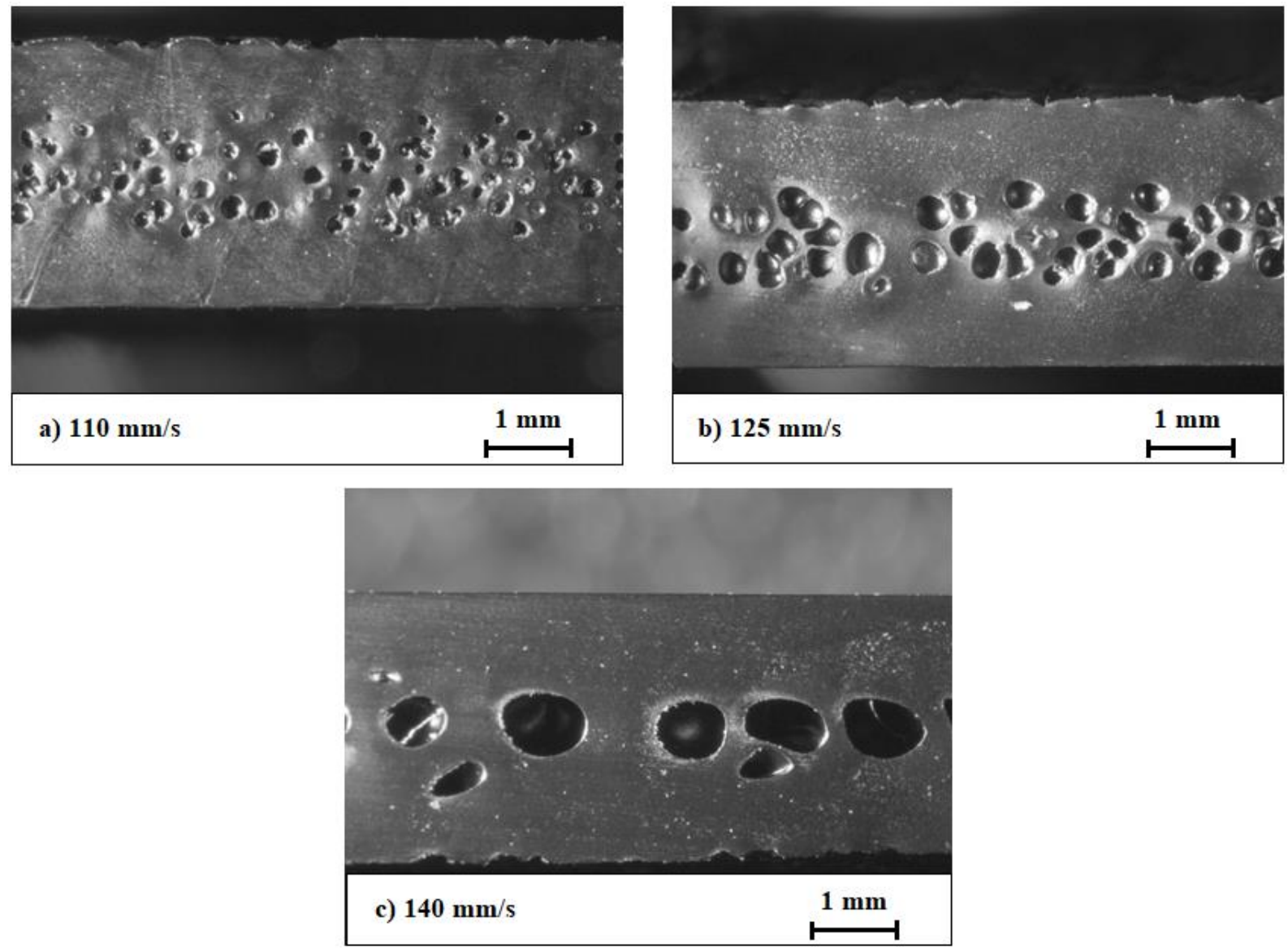

Figure 4. Optical microscope images of PP/CBA foams acquired at different injection speeds: (a) $110 \mathrm{~mm} / \mathrm{s}$, (b) $125 \mathrm{~mm} / \mathrm{s}$, (c) 140 $\mathrm{mm} / \mathrm{s}$.

From Figure 4, an increase of the mean cell size and a decrease of the cell density is notable as the injection speed rises. In order to have a better understanding, the progression of the average cell size, average cell density and mean thickness of the compact outer 
layer of PP/CBA foams were plotted as a function of the injection speed as represented in Figures 5, 6 and 7. From Figure 5, a sharp increase of the mean cell diameter from 191 to $761 \mu \mathrm{m}$ can be observed with a 3.9-fold rise from $110 \mathrm{~mm} / \mathrm{s}$ to $140 \mathrm{~mm} / \mathrm{s}$. As a result, a reduction of the cell density from 369 to 42 number of cells $/ \mathrm{cm}^{2}$, and then a more important gain of about 8.8 -fold is obtained with increasing the injection speed as presented in Figure 6. The monitoring of the compact outer layer thickness revealed a less distinct variation and it can be seen from Figure 7 that a slight increase is observed from 0.97 to 1.13 as the injection speed augments. As a result, the correlation between Figure 5 and Figure 7 allows us to conclude that as the cell diameter increases the thickness of the compact outer layer slightly rises.

In order to get more weight reduction and preventing premature expansion of the gas and silver streaks, it is recommended to increase the injection speed. But when we exceed the optimum speed limit; the cell size become larger. Larger cells cause unwanted undulations or aesthetic defects on the surface. High injection speeds provoke an increase of the melting temperature of PP/CBA due to the more important friction of the polymer with the mold. In this case, the higher melting temperature as the injection speed increases allows the activation of more CBA in a shorter time. As a result, the freeze of the cells are delayed and thus, the cell formation and growth occurs until the final freeze which is observed during the cooling step. Xi et al. (2016) supports that, at the first stage the cells appear at the front of the flow. Then, they move to the top and bottom of the mold surfaces. If the cell completes its growth during the injection flow, the cell diameter cannot expand more because of the continuous flow pressure. But if the injection is performed fast enough before the cells appear, the cells have the possibility to expand as much as the free volume. Fast injection step also allows to fill the mold cavity using less important amount of polymer. (Xi et al. 2016) All these reasons explain how the mean cell size becomes higher in the case of higher injection speeds.

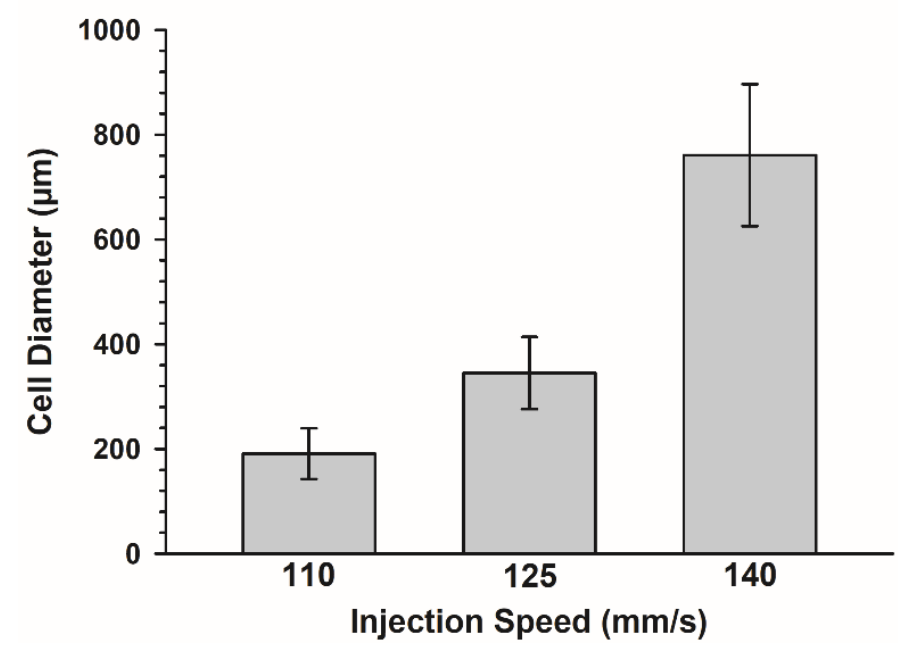

Figure 5. Evolution of the cell diameter of PP/CBA foams as the injection speed increases.

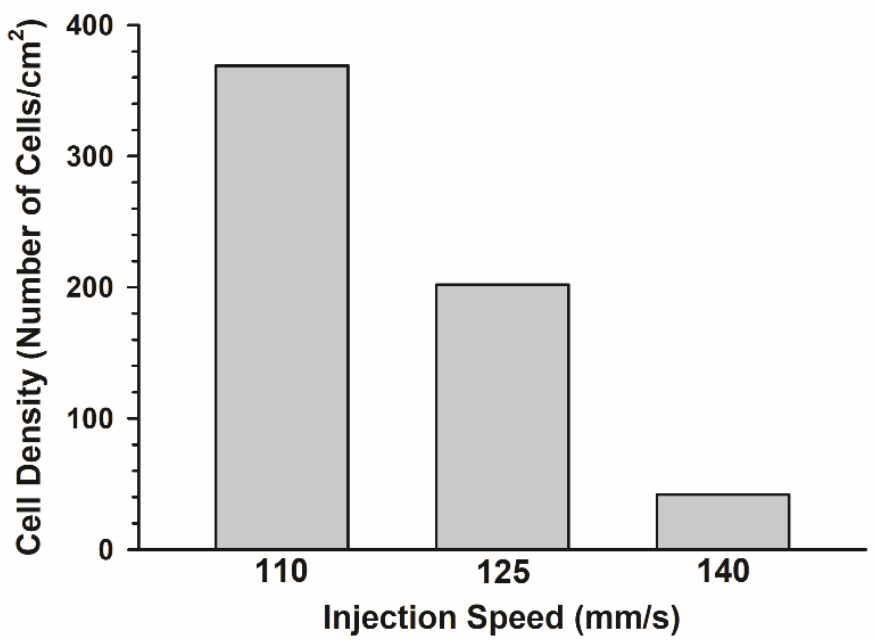

Figure 6. Evolution of the cell density of PP/CBA foams as the injection speed increases. 


\subsubsection{Tensile test results}

Tensile tests of specimens prepared at various injection speeds were performed. The tensile test results of PP/CBA foams prepared at the injection speeds 110,125 and $140 \mathrm{~mm} / \mathrm{s}$ are given in the Table 1 . In particular, the evolution of the elastic modulus and the tensile strength values as the injection speed increases can be monitored from this Table 1. From these results, it can be observed that, as the injection speed increases, the elastic modulus of samples rises from $1081 \mathrm{MPa}$ to $1348 \mathrm{MPa}$. It can be noticed that this evolution is in correlation with the previous microscopy results indicating an increase of the cell diameter and the compact outer layer thickness of PP/CBA foams with the increase of the injection speed. The compact outer layer thickness has an improvement effect on the mechanical properties. Even in experiments between parts of similar density, it is important to state that the cell diameter and the compact layer thickness have a significant effect on the elastic modulus. Furthermore, from Table 1, it can be seen that the tensile strength remains nearly constant as the injection speed rises and it can be concluded that it is independent on the injection speed.

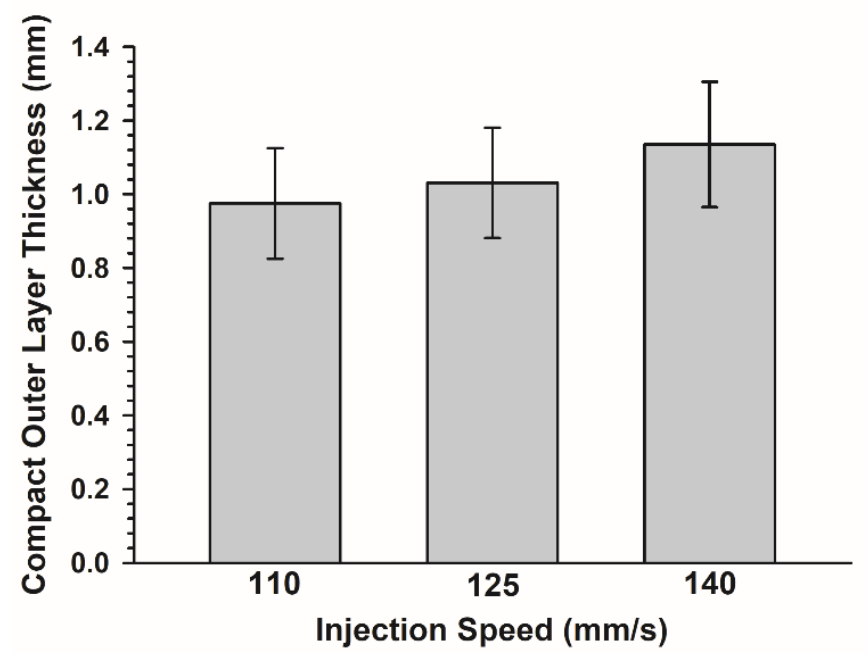

Figure 7. Evolution of the compact outer layer thickness of PP/CBA foams as the injection speed increases.

Table 1. Elastic modulus and tensile strength values of PP/CBA foams obtained at different injection speeds.

\begin{tabular}{ccc}
\hline $\begin{array}{c}\text { Injection speed } \\
(\mathbf{m m} / \mathbf{s})\end{array}$ & $\begin{array}{c}\text { Elastic modulus } \\
(\mathbf{M P a})\end{array}$ & $\begin{array}{c}\text { Tensile strength } \\
(\mathbf{M P a})\end{array}$ \\
\hline 110 & $1081 \pm 127$ & $21.10 \pm 0.5228$ \\
125 & $1109 \pm 75$ & $20.52 \pm 0.3842$ \\
140 & $1348 \pm 22$ & $21.29 \pm 0.0963$ \\
\hline
\end{tabular}

\subsection{Effect of Core Back Distance on the Properties of PP/CBA Foams}

\subsubsection{Optical microscopy results}

Figure 8 shows the optical microscopy pictures of PP/CBA foams prepared at different core back distances (0, 0.7 and $1.5 \mathrm{~mm})$. The aim of this work is to increase of the weight reduction using the core-back system. Figures 6 and 7 showed that the lower cell density and outer layer thickness is observed for the injection speed $110 \mathrm{~mm} / \mathrm{s}$. That's why in this part, the injection speed was fixed at 110 $\mathrm{mm} / \mathrm{s}$ for all experiments. As in the previous case, only one parameter, the core back distance, was modified for the purpose of evaluating its effect on the final properties. Sample sections perpendicular to the surface were examined to detect the microstructure changes and in the sense, the cell size, cell density and thickness of the compact outer layer of PP/CBA foams were determined as a function of the core back distance.

It can be seen from Figure 8 that a net rise of the cell density appears from $0 \mathrm{~mm}$ to $0.7 \mathrm{~mm}$ core back distance, whereas the cell size seems to be stable. As the core back distance is augmented at $1.5 \mathrm{~mm}$, the previous homogeneous microstructure becomes inhomogeneous with the presence of inconsistent cells. Figures 9, 10 and 11 give the evolution of the mean values of the cell diameter, cell density and compact outer layer thickness obtained for PP/CBA samples prepared at different core back distances, using Image J software.

As in the previous section, these results provide a better display for the effect of core back distance on the microstructure properties of PP/CBA foams, within the manufactured part. From Figure 9, the mean cell diameter remains nearly unaltered from 0 to 0.7 mm and a sharp increase is obtained for the sample prepared at a core back distance of $1.5 \mathrm{~mm}$. Furthermore, an optimum mean cell density $\left(924\right.$ cells $\left./ \mathrm{cm}^{2}\right)$ is obtained at a core back distance of $0.7 \mathrm{~mm}$ as revealed in Figure 10. As represented in Figure 11, the average compact 
outer layer thickness decreases from 1.01 to $0.55 \mathrm{~mm}$ as the core back distance increases. As a result, with the increase of the core back distance, the average number and diameter of the cells increase, but the cell structure deteriorates from a critical core back distance which is $0.7 \mathrm{~mm}$ in this work.

Zhang et al. (2014) investigated the properties of high impact polystyrene mixed with different amounts of azodicarbonamide as chemical blowing agent and this deterioration of the cells has been attributed to the continuation of the cell growth and thus, the cell coalescence which causes the formation of collapses. In this study, the cell density which is $924 \mathrm{cells} / \mathrm{cm}^{2}$ at a core back distance of $0.7 \mathrm{~mm}$, drops to 314 cells $/ \mathrm{cm}^{2}$ when the core back distance rises to $1.5 \mathrm{~mm}$. This is due to the coalescence and collapse of cells that continue to grow.
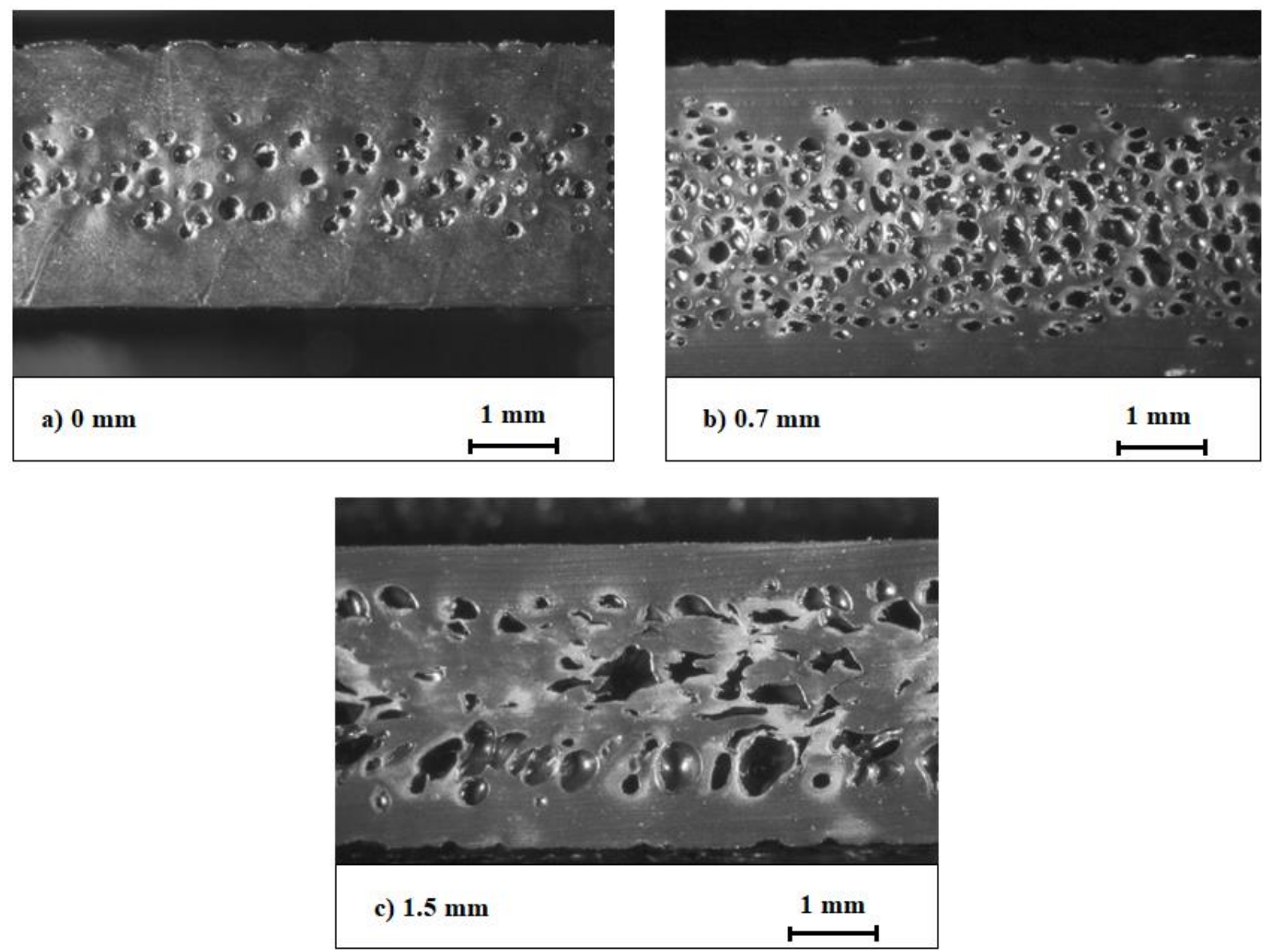

Figure 8. Optical microscope images of PP/CBA foams acquired at different core back distance: a) $0 \mathrm{~mm}$, no core back, b) $0.7 \mathrm{~mm}$ core back position, c) $1.5 \mathrm{~mm}$ core back position.

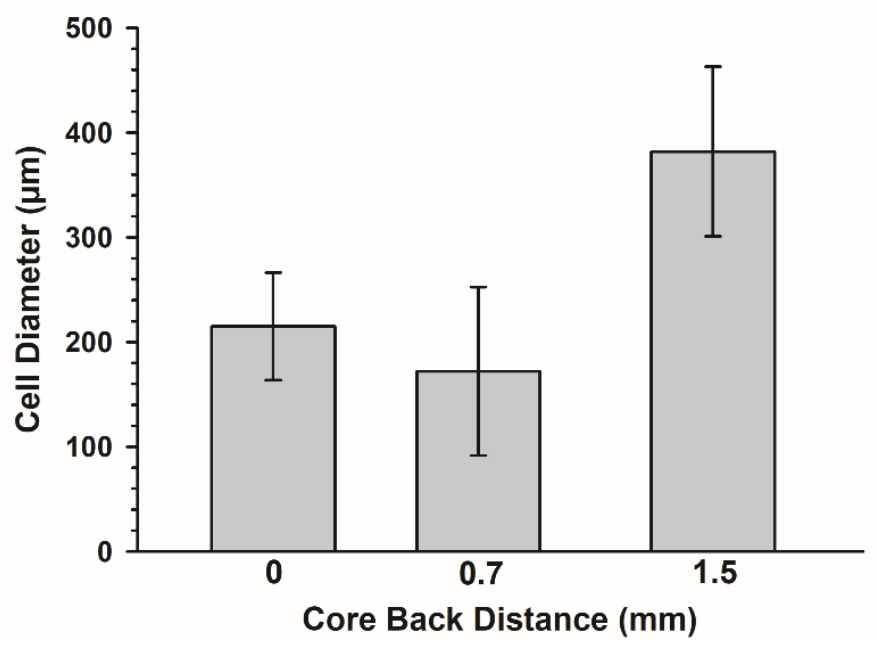

Figure 9. Evolution of the cell diameter of PP/CBA foams as the core back distance increases. 


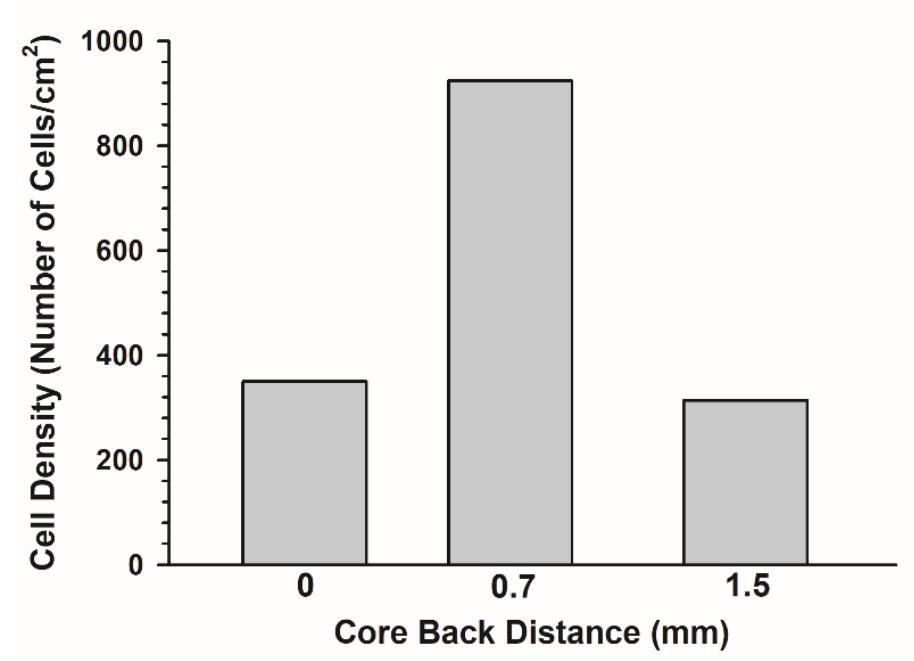

Figure 10. Evolution of the cell density of PP/CBA foams as the core back distance increases.

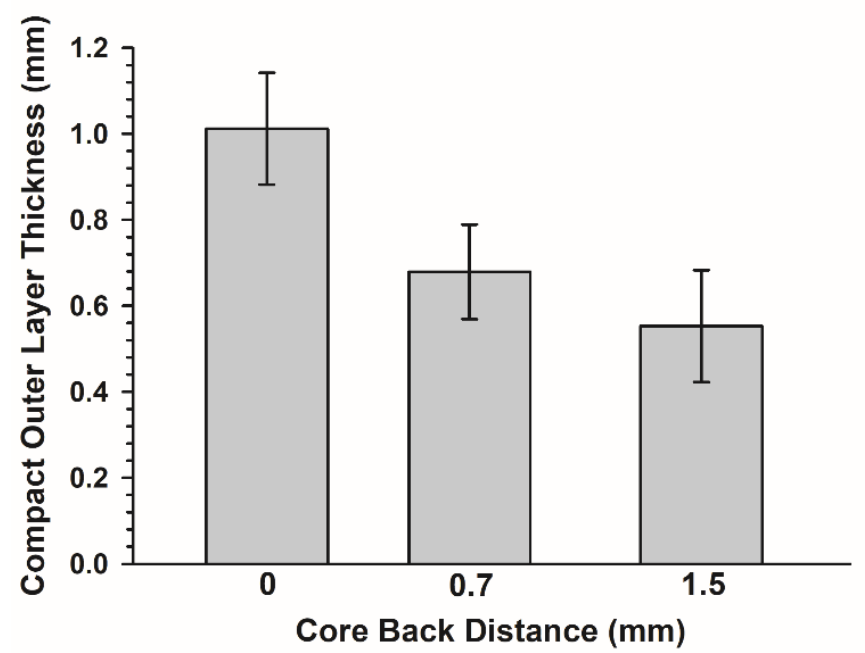

Figure 11. Evolution of the compact outer layer thickness of PP/CBA foams as the core back distance increases.

Table 2. Elastic modulus and tensile strength values of PP/CBA foams obtained at different core back distances.

\begin{tabular}{ccc}
\hline $\begin{array}{c}\text { Core back } \\
\text { distance }(\mathbf{m m})\end{array}$ & $\begin{array}{c}\text { Elastic modulus } \\
(\mathbf{M P a})\end{array}$ & $\begin{array}{c}\text { Tensile strength } \\
(\mathbf{M P a})\end{array}$ \\
\hline 0 & $1069 \pm 29$ & $17.71 \pm 0.3664$ \\
0.7 & $833 \pm 65$ & $14.43 \pm 0.5297$ \\
1.5 & $807 \pm 123$ & $16.41 \pm 0.1288$ \\
\hline
\end{tabular}

\subsubsection{Tensile test results}

In this part, tensile tests of PP/CBA foams produced at different core back distances were carried out. The elastic modulus and the tensile strength values obtained for PP/CBA foams prepared at core back distances of $0,0.7$ and $1.5 \mathrm{~mm}$ were summarized in the Table 2. It can be mentioned from these results that the elastic modulus of samples was reduced from $1069 \mathrm{MPa}$ to $807 \mathrm{MPa}$. Furthermore, as the core back distance increases, a significant correlation with the previous microscopy results indicating an increase of the cell diameter and a decrease of the compact outer layer thickness of PP/CBA foams can be detected. As in the previous part, the compact outer layer thickness is the most important parameter which influences the final mechanical properties. Indeed, despite of a rise of the cell diameter, the drop of the compact layer thickness have a determining effect on the elastic modulus which decreases too. Another important point that can be noticed from Table 2 is the tensile strength of PP/CBA foams which not seem to be very influenced by the core back distance. Actually, specimens that were produced without mold opening (core back) behave similarly to compact plastics in 
the tensile test. However, when mold opening system is used, they form a three-layer structure similar to the sandwich structure. The middle zone and outer layers act like two completely different materials. In this work, during the tensile tests, the compact outer layer is elongated at a constant rate until it broke, but the porous area in the center of the parts broke off in the first seconds of the test exhibiting a fragile behavior. Saiz-Arroyo et al. (2012) demonstrated that stiffer materials can be obtained only in the case of relative densities higher than 0.4 in the case of PP/CBA foams.

\section{Conclusions}

In this work, PP/CBA foams were produced at different injection speeds $(110,125$ and $140 \mathrm{~mm} / \mathrm{s})$ and core back distances $(0,0.7$ and $1.5 \mathrm{~mm}$ ) by plastic injection method using a chemical foaming agent. In this way, optimum process parameters can be determined for the production of lighter parts in the automotive industry, with optimum mechanical and microstructure properties. The results showed that even minor changes in the process parameters cause significant alterations in the mechanical properties and microstructure of the manufactured part. The increase of the injection speed induced a rise of the cell diameter, the skin layer thickness and the elastic modulus. The core back distance impact on the microstructure was more important due to the apparition of a critical core back distance above which, the cells started to collapse and lose their circularity. The working range of the process parameter in which the same product can be manufactured with the chemical foaming process is much narrower compared to standard injection molding process. However, the products manufactured in the industry are not desired to be different from each other. For these reasons, besides the correct injection adjustment; using additional control mechanisms that control the process during the injection and control the quality of the products prepared after injection is critical to the industrialization of a chemical foamed product.

\section{Acknowledgements}

Tofaş Türk Otomobil Fabrikası A.Ş., Farplas Otomotiv A.Ş. and Karel Kalıp San. A.Ş. are gratefully acknowledged for the production of PP/CBA foams at different processing conditions. The Scientific Research Projects Units of Bursa Technical University (under the contract number of 172L09) are also gratefully acknowledged for their financial support.

\section{References}

Ameli, A., Jahani, D., Nofar, M., Jung, P. U., Park, C. B. (2014). Development of high void fraction polylactide composite foams using injection molding: mechanical and thermal insulation properties. Composites Science and Technology, 90, 88-95. doi:10.1016/j.compscitech.2013.10.019

Ameli, A., Nofar, M., Jahani, D., Rizvi, G., Park, C. B. (2015). Development of high void fraction polylactide composite foams using injection molding: crystallization and foaming behaviors. Chemical Engineering Journal, 262, 78-87. doi:10.1016/j.cej.2014.09.087

Chu, R. K. M., Mark, L. H., Jahani, D., Park, C. B. (2016). Estimation of the foaming temperature of mold- opening foam injection molding process. Journal of Cellular Plastics, 52(6), 619-641. doi:10.1177/0021955X15592069

Ishikawa, T. \& Ohshima, M. (2011). Visual observation and numerical studies of polymer foaming behavior of polypropylene/carbon dioxide system in a core-back injection molding process. Polymer Engineering and Science, 51(8), 1617-1625. doi:10.1002/pen.21945

Ishikawa, T., Taki, K., Ohshima, M. (2012). Visual observation and numerical studies of $\mathrm{N}_{2} \mathrm{vs} . \mathrm{CO}_{2}$ foaming behavior in core-back foam injection molding. Polymer Engineering and Science, 52(4), 875-883. doi:10.1002/pen.22154

Jahani, D., Ameli, A., Jung, P. U., Barzegari, M. R., Park, C. B., Naguib, H. (2014). Open-cell cavity integrated injection-molded acoustic polypropylene foams. Materials \& Design, 53, 20-28. doi:10.1016/j.matdes.2013.06.063

Lyu, M. Y., Choi, T. G. (2015). Research trends in polymer materials for use in lightweight vehicles. International Journal of Precision Engineering and Manufacturing, 16, 213-220. doi:10.1007/s12541-015-0029-X

Miyamoto, R., Yasuhara, S., Shikuma, H. (2014). Preparation of micro/nanocellular polypropylene foam with crystal nucleating agents. Polymer Engineering and Science, 54(9), 2075-2085. doi:10.1002/pen.23758

Reglero Ruiz, J. A., Vincent, M., Agassant, J.-F. (2016). Numerical modeling of bubble growth in microcellular polypropylene produced in a core-back injection process using chemical blowing agents. International Polymer Processing, 31(1), 26-36. doi: $10.3139 / 217.3129$

Reglero Ruiz, J. A., Vincent, M., Agassant, J.-F., Claverie, A., Huck, S. (2015). Morphological analysis of microcellular PP produced in a core-back injection process using chemical blowing agents and gas counter pressure. Polymer Engineering and Science, 55(11), 2465-2473. doi:10.1002/pen.24136 
Ries, S., Spoerrer, A., Altstaedt, V. (2013). Foam injection molding of thermoplastic elastomers: Blowing agents, foaming process and characterization of structural foams. AIP Conference Proceedings; 15-19 July 2013; Nuremberg, Germany. AIP: 1593.

Ruiz, J. R., Vincent, M., Agassant, J., Sadik, T., Pillon, C., Carrot, C. (2015). Polymer foaming with chemical blowing agents: Experiment and modeling. Polymer Engineering and Science, 55(9), 2018-2029. doi:10.1002/pen.24044

Saiz-Arroyo, C., de Saja, J. A., Velasco, J. I., Rodriguez-Perez, M.A. (2012). Moulded polypropylene foams produced using chemical or physical blowing agents: structure-properties relationship. Journal of Materials Science, 47, 5680-5692. doi:10.1007/s10853-012$6357-7$

Shaayegan, V., Wang, C., Costa, F., Han. S., Park, C. B. (2017). Effect of the melt compressibility and the pressure drop rate on the cell- nucleation behavior in foam injection molding with mold opening. European Polymer Journal, 92, 314-325. doi:10.1016/j.eurpolymj.2017.05.003

Sporrer, A. N. J. \& Altstadt, V. (2007). Controlling morphology of injection molded structural foams by mold design and processing parameters. Journal of Cellular Plastics, 43(4-5), 313-330. doi:10.1177/0021955X07079043

Stumpf, M., Sporrer, A., Schmidt, H. W. (2011). Influence of supramolecular additives on foam morphology of injection-molded i-PP. Journal of Cellular Plastics, 47(6), 519-534. doi:10.1177/0021955X11408769

Tomasko, D. L., Burley, A., Feng, L., Yeh, S. K., Miyazono, K., Nirmal-Kumar, S., Kusaka, I., Koelling, K. (2009). Development of $\mathrm{CO}_{2}$ for polymer foam applications. The Journal of Supercritical Fluids, 47(3), 493-499. doi:10.1016/j.supflu.2008.10.018

Wang, L., Ishihara, S., Hikima, Y., Ohshima, M., Sekiguchi, T., Sato, A., Yano, H. (2017). Unprecedented development of ultrahigh expansion injection-molded polypropylene foams by introducing hydrophobic-modified cellulose nanofibers. ACS Applied Materials \& Interfaces, 9(11), 9250-9254. doi:10.1021/acsami.7b01329

Wu, H., Zhao, G., Wang, J., Wang, G., Zhang, W. (2019). Effects of process parameters on core-back foam injection molding process. eXPRESS Polymer Letters, 13(4), 390-405. doi:10.3144/expresspolymlett.2019.32

Wu, H., Zhao, G., Wang, G., Zhang, W., Li, Y. (2018). A new core-back foam injection molding method with chemical blowing agents. Materials \& Design, 144, 331-342. doi:10.1016/j.matdes.2018.02.043

Xi, Z., Chen, J., Liu, T., Zhao, L., Turng, L. (2016). Experiment and simulation of foaming injection molding of polypropylen e/nanocalcium carbonate composites by supercritical carbon dioxide. Chinese Journal of Chemical Engineering, 24(1), 180-189. doi:10.1016/j.cjche.2015.11.016

Zhang, Z. X., Li, Y. N., Xia, L., Ma, Z. G., Xin, Z. X., Lim, J. K. (2014). Fabrication of superhydrophobic film by microcellular plastic foaming method. Applied Physics A, 117, 755-759. doi:10.1007/s00339-014-8615-9

Zhao, J., Zhao, Q., Wang, C., Guo, B., Park, C. B., Wang, G. (2017). High thermal insulation and compressive strength polypropylene foams fabricated by high-pressure foam injection molding and mold opening of nano-fibrillar composites. Materials \& Design, 131, 111. doi:10.1016/j.matdes.2017.05.093 